\title{
Effect Of Thermal Annealing On The Optical Properties Of Thin Films Of Polymer Blend (PMMA:PVC:PS)
}

\author{
Ali N. Sabbar ${ }^{1 *}$, Karar M.Talib ${ }^{2}$, and Hassan T. Badh ${ }^{1}$ \\ ${ }^{1}$ Department of Physics, College of Science, Al Muthanna University, Iraq \\ ${ }^{2}$ College of Dentistry, Al Muthanna University, Iraq \\ "Corresponding author: asabbar84@gmail.com
}

Received:20/11/2017, Accepted:21/1/2018, published: 18/03 /2018

DOI: 10.52113/2/05.01.2018/1-7

\begin{abstract}
In this paper, we report upon preparation and optical properties of the polymer blend (50\%PMMA:25\%PVC:25\%PS) thin films. The thin films have been prepared with specific ratios using the casting technique at normal weather conditions. The films were subjected to heat treatment in varying temperatures for three hours. The results showed that increase thermal annealing temperature leads to decrease values of the direct and indirect energy gap, but increase the extinction coefficient and optical conductivity. The refractive index, real and imaginary dielectric constants showed a heterogeneous behaviour. Thermal annealing by $80{ }^{\circ} \mathrm{C}$ and up leads to deformation the thin films.
\end{abstract}

(C2018 Al Muthanna University. All rights reserved

Keywords: Thin films, optical properties, annealing, casting method, polymer blend.

\section{Introduction}

Because of the wide use of the polymeric material in our life, there are many studies to enhance their properties by different ways: addition salts, addition laser dyes, mixing and thermal annealing [1]-[3]. Polymer blends are a mixture of chemically different polymers or copolymers with no covalent bonding between them. Polymer blending imparts some new characteristics leading to formation new materials with enhanced properties [4].
There are many studies on polymer PVC, PS and PMMA for their wide applications in our daily lives. The previous studies in optics field, showed that the thermal treating works to reduce the energy gap of polymeric materials, and adding some impurities would reduce the energy gap and increase the values of optical constants [4],[5].

Thermal annealing of DCM-PVC and DCMPS thin films showed that values of the optical direct-band gap are inversely proportional to annealing temperature, while in case indirect electronic transition the band gap increases 
with increasing of annealing temperature [6],[7].

The purpose of this work is to study the effect of thermal annealing on the optical properties of polymer blend (50\%PMMA:25\%PVC:25\%PS) thin films.

\section{Experimental procedure}

The samples prepared as follows: a powder of $(0.25 \mathrm{gm} \mathrm{PVC}+0.25 \mathrm{gm}$ PS $+0.50 \mathrm{gm}$ PMMA) has been dissolved in $(15 \mathrm{ml})$ of Tetrahydrofuran (THF). The solution has been mixed by using magnetic heater stirrer for three hours to obtain a homogeneous solution. The mixture has been cast on a glass substrate at room temperature. The samples have been placed in the oven for three hours. Each sample is placed separately in the electric oven at a different temperature as following (40, 50, $\left.60,70,80^{\circ} \mathrm{C}\right)$. The thickness of the prepared thin films $(1-2 \mu \mathrm{m})$ is measured using a handheld gauge. The UV-visible double-beam spectrophotometer has been used to test the absorption and reflection spectrum of samples in range (370-900nm). Practically, for polymeric materials it is possible to calculate the value of energy gap $\left(E_{g}\right)$ by the formula [8],[9]:

$$
\alpha E=A\left(E-E_{g}\right)^{m}
$$

Where $\mathrm{A}$ is a proportional constant, $E=h v$ is the photon energy, $\alpha$ is absorption coefficient and $\mathrm{m}$ is exponential constant, for allowed direct transition $\mathrm{m}=1 / 2$ and for allowed indirect transition $\mathrm{m}=2$.
The value of reflectance $(\mathrm{R})$ is determined by UV-Visible double beam spectrophotometer and the linear refractive index (n) estimated by equation [10]:

$n=\sqrt{\frac{4 R}{(1-R)^{2}}-k^{2}}+\frac{1+R}{1-R}$

Where $k$ is the extinction coefficient, can be found by equation [11]:

$k=\frac{\alpha \lambda}{4 \pi}$

The real and imaginary dielectric constants are calculated using equations [12]:

$\varepsilon_{r}=n^{2}-k^{2}$

$\varepsilon_{i}=2 n$

The value of optical conductivity is calculated using equation [13]:

$\sigma=\frac{\alpha n c}{4 \pi}$

Where (c) is the speed of light in vacuum.

\section{Results and discussion}

The absorbance and the reflectance spectrum of polymer blend (50\% PMMA :25\%PVC:25\% PS) thin films in the wavelength range $(370-900 \mathrm{~nm})$ for different temperatures of thermal annealing are shown in figures (1) \& (2). 


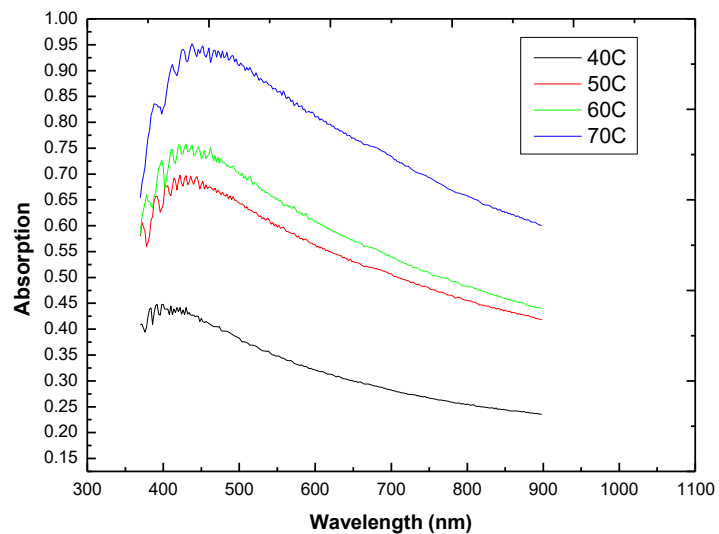

Fig. 1 Optical absorption spectra versus wavelength

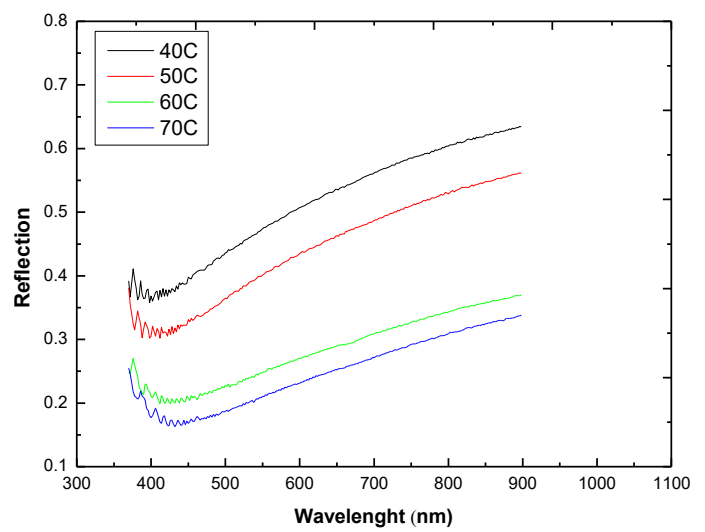

Fig. 2 Reflectance spectra versus wavelength

Figure (1) shows for the short wavelength (370 to $425 \mathrm{~nm}$ ) the absorption increase as increasing wavelength and for longer wavelength it seems increasing the wavelength leads to decreasing the absorbance. The absorption increased with increasing thermal temperature.

The reflectance decreases with increasing temperature as shown in figure (2). This is also consistent with Mohammed's results [7].

Figure (3) shows relation between absorption coefficient and photon energy of polymer blend (50\%PMMA:25\%PVC:25\%PS) thin films that treated thermally in the range (40-70 $\left.{ }^{\circ} \mathrm{C}\right)$.

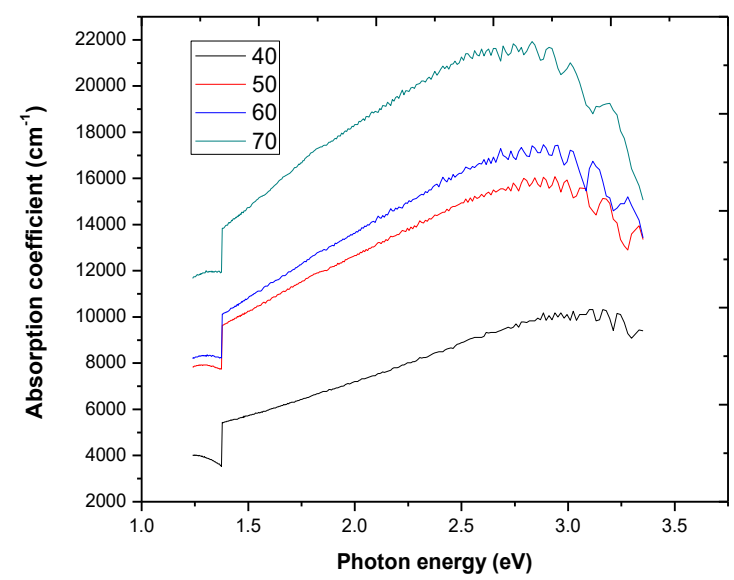

Fig.3 Absorption coefficient versus photon energy

The absorption coefficient increased with increasing the temperature of thermal annealing.

The transitions were indirect for thin films treated by $40{ }^{\circ} \mathrm{C}$, while thin films treated by $\left(50,60 \& 70^{\circ} \mathrm{C}\right)$ the transitions were direct. As shown in figure the absorption coefficient increases as increasing photon energy until 2.9 $\mathrm{eV}$, and then start decreases. There is a good agreement with researcher Reddeppa [14].

The samples that treated by $80{ }^{\circ} \mathrm{C}$ and up were deformed. The variation of $(\alpha \mathrm{E})^{2}$ and $(\alpha \mathrm{E})^{1 / 2}$ as a function of photon energy were shown in figures (4) \& (5) that, in turn, illustrates the effects of annealing on the values of energy gap for direct and indirect-allowed transitions. 


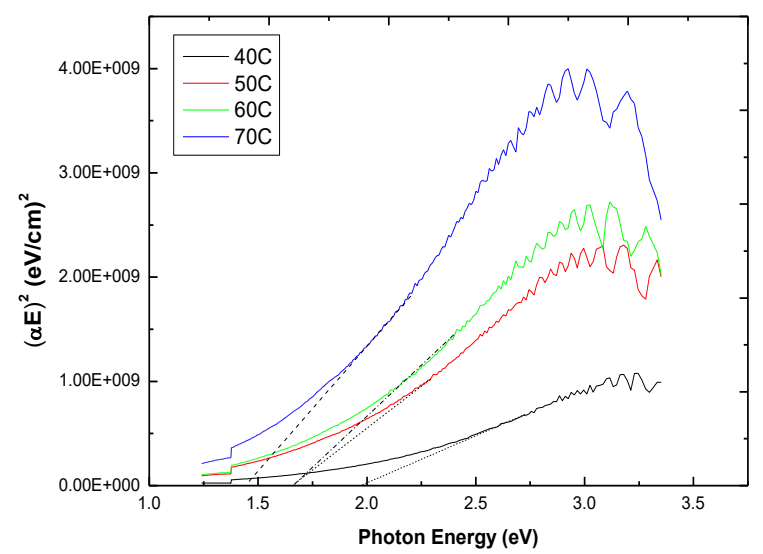

Fig. 4 Relation between $(\alpha E)^{2}$ and photon energy

The empirical results indicate to reduce the energy gap values by increasing thermal annealing temperature. Due to increase applied thermal annealing from 40 to $70{ }^{0} \mathrm{C}$ the values of direct-energy gap reduced from 2 to $1.5 \mathrm{eV}$. This is agrees with Bhatti's result, that observed by increase thermal annealing (70$\left.110^{\circ} \mathrm{C}\right)$, the energy band gap decrease for each film [15].

Increase applied thermal annealing indicate to reducing the values of the indirect-energy gap from 0.5 to $0.8 \mathrm{eV}$.

The real $\left(\varepsilon_{\mathrm{r}}\right)$ and imaginary $\left(\varepsilon_{\mathrm{i}}\right)$ parts of the dielectric constant related to the refractive index and extinction coefficient, see equations (4) and (5). Figures (6) and (7) show $\left(\varepsilon_{\mathrm{r}}\right)$ and $\left(\varepsilon_{\mathrm{i}}\right)$ values as a function to the wavelength for different degrees of annealing.

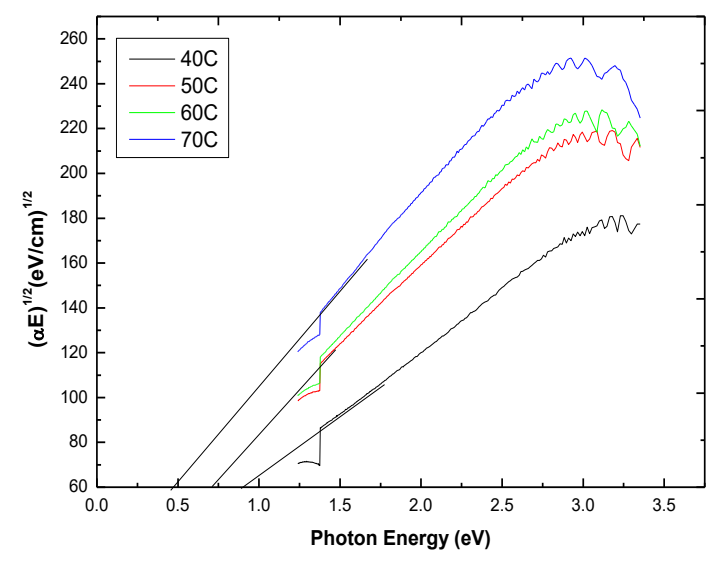

Fig. 5 Relation between $(\alpha E)^{1 / 2}$ and photon energy

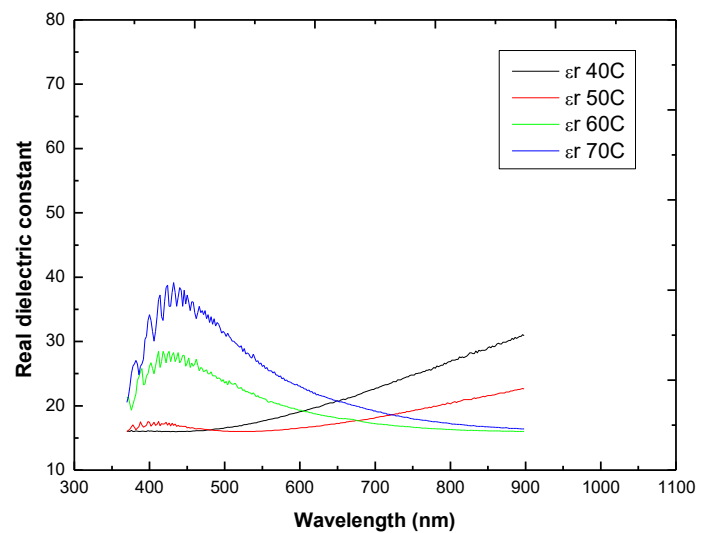

Fig. 6 Real part of dielectric constant as a function of wavelength

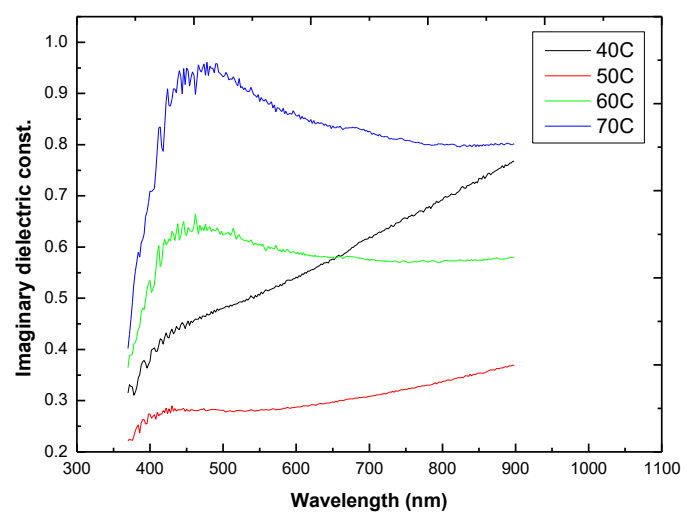

Fig. 7 Imaginary part of dielectric constant as a function of wavelength

The values of real dielectric constant increase with increasing wavelength when the thin 
films treated by $\left(40 \& 50{ }^{\circ} \mathrm{C}\right)$, while when treatment them by $\left(60 \& 70{ }^{\circ} \mathrm{C}\right)$ they have different manner.

The linear refractive index and extension coefficient also affected by the applied temperature of thermal annealing, as shown in figures (8) \& (9).

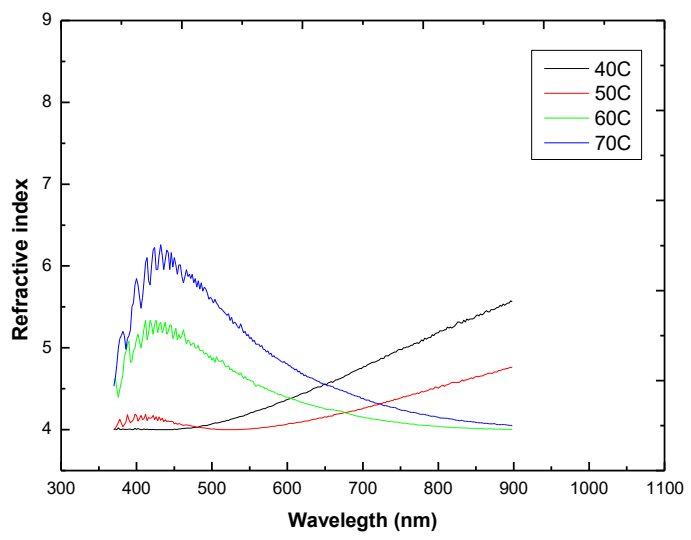

Fig. 8 Refractive index as a function of wavelength

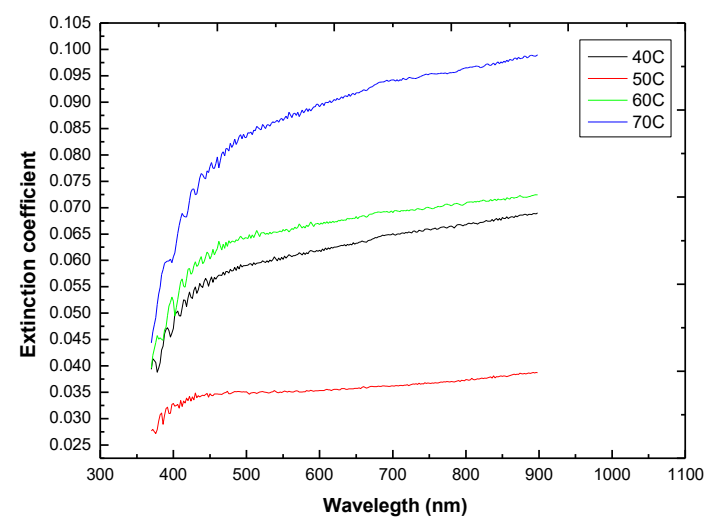

Fig. 9 Extinction coefficient as a function of wavelength

From figure (8) we observe a change in the refractive index behavior according to the annealing temperature. Figure (9) shows an increase in the temperature of annealing increases the extinction coefficient in the range 370 to $900 \mathrm{~nm}$.
The relation between optical conductivity and photon energy shown in figure (10), which illustrate effect of the thermal annealing for polymer blend (50\%PMMA:25\%PVC:25\%PS) thin films.

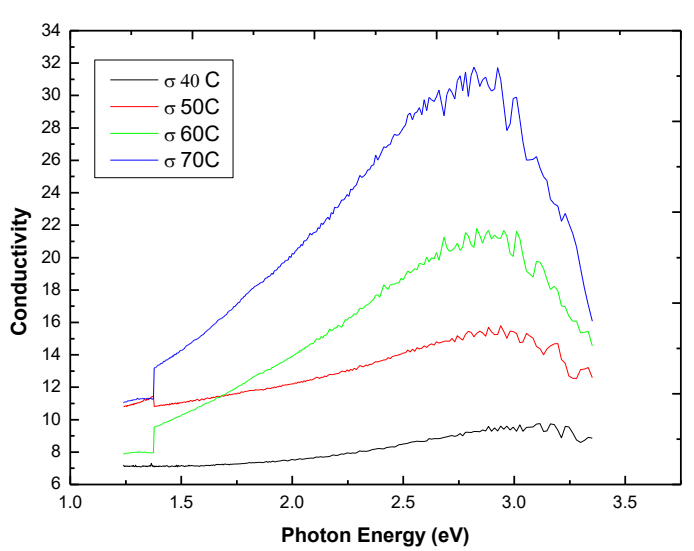

Fig. 10 Optical conductivity as function of photon energy

The optical conductivity increases according to increasing the applied temperature of thermal annealing this behavior is agreement with Reddeppa's result [14] and in another side, it is increased with increasing photon energy in the range (1.4 to $2.9 \mathrm{eV})$.

\section{Conclusions}

We conclude that increasing the emperature of annealing from $40{ }^{\circ} \mathrm{C}$ to $70{ }^{\circ} \mathrm{C}$ for polymer blend (50\%PMMA:25\%PVC:25\%PS) leads to:

1. Increase the direct electronic transmissions.

2. Decrease the indirect energy gap from 2 to $1.5 \mathrm{eV}$

3. Decrease the direct energy gap from 0.9 to $0.4 \mathrm{eV}$. 
4. Increase the extinction coefficient and optical conductivity.

5. The refractive index, real and imaginary dielectric constants showed a heterogeneous behavior.

Finally, thermal annealing by $80{ }^{\circ} \mathrm{C}$ and up leads to deformation samples.

\section{Acknowledgment}

The authors would like to thank Ahmed N. Mohamed and Akeel Sh. Tuhaiwer in the department of physics/ Muthanna University for their continuous help during the period of the work. Special thanks to Dr.Jafer F. Odah for his advice in the writing instructions.

\section{References}

[1] Oraibi, A. H., 2014, "Effect of addition AgNO3 on some optical properties of polystyrene", Journal of Babylon University/Engineering Sciences, Vol.(22), No.(2), pp:444-449.

[2] Al-Wattar, A. J., Chiad, B. T. and Taleb, A. J., 2007, "Incident Laser Power and Concentration Effects on the Fluorescence of DCM Dye in PMMA Polymer", Iraqi J. Laser, Part A, Vol. (6), pp:1- 4.

[3] Habubi, N. F., Abed, B. H., Chiad, S. S., 2012, "Optical properties of $\mathrm{BaCl} 2$ doped poly (vinyl alcohol) films", Iraqi Journal of Physics, Vol.(10), No.(17), PP. 18-22.
[4] Kumar, K. K., Ravi, M., Pavani, Y., Bhavani, S., Sharma, A.K. and Rao, V.V., 2011, "Investigations on the effect of complexation of $\mathrm{NaF}$ salt with polymer blend (PEO/PVP) electrolytes on ionic conductivity and optical energy band gaps”, Physica B, 406, pp:1706-1712.

[5] Abdullah, O. Gh., Tahir, D. A. and Aziz, Sh. B., 2010, "Optical and Electrical Properties of Polyvinyl-Chloride (Pvc) Films", Iraqi Journal of Science, Vol.(51), No.(2), pp: 295-300.

[6] Hussian, Sh.K., 2017, "Effect of annealing temperature on the optical properties of DCM-PVC doped with $\mathrm{TiO} 2$ nanoparticles thin films", AL-Muthanna Journal of Pure Science, Vol.(4), No.(1), pp:73-84.

[7] Mohamed, A.N., 2016, "Effect of annealing temperature on the optical properties of DCM-PS doped with $\mathrm{TiO} 2$ nanoparticles thin films", International Journal of Scientific \& Engineering Research, Vol.(7), No.(3), pp:711-716.

[8] Park, J., Shin, Ch. , Lee, S., Kim, S., Jung, J., Balaji, N., Dao, V.A., Lee, Y. J. and Junsin, Yi, 2015, "Effect of thermal annealing on the optical and electrical properties of boron doped a-SiOx:H for thin-film silicon solar cell applications", Thin Solid Films, TSF-34068, pp:1-5. 
[9] Xue, S.W., Zu, X.T., Zhou, W.L., Deng, H.X., Xiang, X., Zhang, L. and Deng H., 2008, "Effects of post-thermal annealing on the optical constants of $\mathrm{ZnO}$ thin film”, Journal of Alloys and Compounds, 448, pp:21-26.

[10] Al-Jawad, S. M, Al-Shareefi, A.F. and Judran, A.K., 2011, "Effect of thickness on optical and electrical properties of $\mathrm{ZnO}$ Prepared by CBD”, Iraqi Journal of Applied Physics, Vol.(7), No.(1), pp:11-16.

[11] French, R.H., Rodr1'guez-Parada, J.M., Yang, M.K., Derryberry, R.A. and Pfeiffenberger, N.T., 2011, “Optical properties of polymeric materials for concentrator photovoltaic system s", Solar Energy Materials \& Solar Cells, 95, pp: $2077-2086$.

[12] Caglar, M., Ilican, S., Caglar, Y., Sahin Y., Yakuphanoglu, F. and H“ur, D., 2008, "A spectroelectrochemical study on a single-oscillator model and optical constants of sulfonated polyaniline film", Spectrochimica Acta Part A, 71, pp: 621627.

[13]Al-Mansaf, A.I., 2011, “Optical Properties of Dye (P- Naphtholbenzein $(\alpha)$ )", Journal of Basrah Researches ((Sciences)) Vol. (37). No. (3) A, pp:43-48.

[14]Reddeppa, N. , Sharma, A.K. , Narasimha, V.V.R. , Chen, W., 2013, "Preparation and characterization of pure and $\mathrm{KBr}$ doped polymer blend (PVC/PEO) electrolyte thin films", Microelectronic Engineering, 112, pp:57-62.

[15] Bhatti, Im. N., Banerjee, M. and Bhatti, I. N., 2013, "Effect of Annealing and Time of Crystallization on Structural and Optical Properties of PVDF Thin Film Using Acetone as Solvent", IOSR Journal of Applied Physics, Vol.4, No.4, PP: 42-47. 